\title{
JOURNAL OF HEALTH SCIENCES AND MEDICINE
}

\author{
Sağlık Bilimleri ve Tıp Dergisi
}

J Health Sci Med 2019; 2(2): 54-57

Research Article / Araştırma Makalesi

\section{Enfeksiyon kontrol önlemlerine ilişkin klinik karar destek sistemlerinin hazırlanması ve etkililiğin değerlendirilmesi}

\section{Preparation of clinical decision support systems related to infection control measures and evaluation of effectiveness}

\author{
(1) Fatih Temoçin ${ }^{1}$, (1) Hatice Köse', (1) Aziz Ahmet Surel ${ }^{2}$ \\ ${ }^{1}$ Yozgat Şehir Hastanesi, Enfeksiyon Hastalıkları ve Klinik Mikrobiyoloji Bölümü, Yozgat, Türkiye \\ ${ }^{2}$ Yozgat Şehir Hastanesi, Genel Cerrahi Kliniği, Yozgat, Türkiye
}

\section{ÖZ}

Amaç: Hastane enfeksiyon yayılma hızları, sağlıktaki en önemli kalite göstergelerinden biri olarak kabul edilmektedir. Enfeksiyon kontrol komitesi tarafından yürütülen çalıșmalarda laboratuvar, enfeksiyon kontrol ekibi ve hekim arasındaki iletişim çok önemlidir. Hastane enfeksiyonlarını önleme çalışmalarında hastane bilişim ve iletişim teknolojilerinin kullanımı çok yenidir. Biz bu çalışmada; Yozgat Şehir Hastanesi'nde, bilgi yönetim sistemine entegre ettiğimiz, enfeksiyon kontrol önlemlerini iceren klinik karar destek sistemlerinin (KDS) hazırlanma süreci ve etkinliğini sunmayı amaçladık

Gereç ve Yöntem: Hastane bilgi yönetim sistemi (HBYS) yazılımına belirlediğimiz tetikleyici faktörler kodlanarak, her bir tetikleyiciye özel uyarılar hazırladık. Daha önceden tarafımızca tanımlanıp yazılım sistemine kodlanılan bir tetikleyici faktör devreye girdiğinde, HBYS sistemi üzerinden hasta ile ilişkili işlem yapan tüm sağlık çalışanlarına (kendi hekimi, konsültasyonda değerlendiren hekimi, hemşiresi, hastayı gören diyetisyen ve fizyoterapist gibi yardımcı sağlık personeli) belirlediğimiz uyarılar görünmektedir.

Bulgular: Hastanemizde, enfeksiyon kontrol önlemlerine yönelik hazırladığımız KDS'ler kullanıma girdikten sonraki dönem ve kullanılmadan önceki dönem karșılaștırıldığında, herhangi bir kültüründe izolasyon uygulamayı gerektirecek bir mikroorganizma üreyen hastaya ulaşma süremiz ve izolasyona başlama süremiz belirgin olarak azalmıştır.

Sonuç: Hazırladığımız KDS tasarımımızın, dünya çapında, sağlık politikalarının üst sıralarında yer alan hastane enfeksiyonlarını önleme çabalarına, olumlu bir katkı sağlayacağı düşüncesindeyiz. Bu alanda, farklı çalışmalar ve uygulamaların geliștirilmesi, günümüz hastane teknolojilerinin sağladığı imkânlar sayesinde, her alanda karar destek sistemlerinin, hasta ve çalışan güvenliğini arttıracak şekilde planlanarak yaygınlaştırılması gerekmektedir.

Anahtar Kelimeler: Karar destek sistemi, izolasyon önlemleri, hastane enfeksiyonları

\begin{abstract}
Aim: Spreading rate of hospital infections is one of the most important quality indicators of health. In studies conducted by the infection control committee, communication between the laboratory, the infection control team, and the physician is significant. In studies of preventing hospital infections, the use of hospital information and communication technologies is recent. In this study, we aimed to provide the process and effectiveness of clinical decision support systems (DSS) in infection control measures integrated into the information management system in Yozgat City Hospital.
\end{abstract}

Material and Method: In the hospital information management system (HIMS) software, we prepared special warnings for each trigger by coding the triggering factors. When a trigger factor that we encode into the software system is activated, all healthcare workers who are involved with the patient through the HIMS (patient's doctor, consultant physician, nurse, and allied health personnel such as a dietician and physiotherapist) saw the warning signs.

Results: When we compared the period before and after the use of DSSs for infection control preventions in our hospital, our time to reach the patient whose culture produces microorganism that requires isolation and the time to begin isolation has decreased considerably.

Conclusion: We believe that our DSS design will provide a positive contribution to efforts to prevent hospital infections that are prioritized in health policies around the world. In this area, decision support systems in order to increase patient and employee safety should be planned and disseminated through the development of different studies and applications with the facilities provided by today's hospital technologies.

Keywords: Decision support system, isolation precautions, hospital infections

Sorumlu Yazar: Fatih Temoçin, Yozgat Şehir Hastanesi, Enfeksiyon Hastalıkları ve Klinik Mikrobiyoloji Bölümü, 66100, Yozgat E-posta: ftemucin@yahoo.com.tr

Geliş Tarihi: 09.09.2018 Kabul Tarihi: 22.11.2018 Doi: 10.32322/jhsm.458438

Bu yazının özeti “Enfeksiyon Kontrol Önlemlerine İlişkin Klinik Karar Destek Sistemlerinin Hazırlanması ve Etkililiğin Değerlendirilmesi” ismi ile 7. Uluslararası sağlıkta performans ve kalite kongresinde sunulmuştur (10-13 Ocak 2018 Belek/Antalya).

Cite this article as: Fatih Temoçin, Hatice Köse, Aziz Ahmet Surel. Enfeksiyon kontrol önlemlerine ilişkin klinik karar destek sistemlerinin hazırlanmast ve etkililiğin değerlendirilmesi. J Healt Sci Med 2019; 2(2): 54-57. 


\section{GíRiş}

Günümüzde gittikçe önem kazanan hastane enfeksiyonları, modern tıbbın en önemli problemleri arasındadır. Hastane enfeksiyon yayılma hızları, sağlıktaki en önemli kalite göstergelerinden biri olarak kabul edilmektedir. Sağlık çalışanları, enfeksiyon etkenlerine karşı kendilerini korumak ve ayrıca diğer hastaların etkilenmemelerini sağlamak için önlemler almalıdır. $\mathrm{Bu}$ önlemler arasında bazı enfeksiyon etkenlerine karşı izolasyon önlemlerini almak çok önemli bir yer oluşturur. Sağlık çalışanlarının enfeksiyon kontrol yöntemlerine uymaları hastane enfeksiyonlarını en aza indirme açısından önemlidir (1). Enfeksiyon kontrol komitesi tarafindan yürütülen çalışmalarda, laboratuvar, enfeksiyon kontrol ekibi ve hekim arasındaki iletişim çok önemlidir. Burada yaşanacak ufak bir aksaklık, yapılması gereken uygulamalarda gecikmeye ve doğal olarak da hastane enfeksiyon oranlarında artışlara neden olmaktadır.

Bilişim ve iletişim teknolojileri hayatımızın her alanını ve aşamasını etkilediği gibi, sağlık hizmetlerinin kalitesinide önemli derecede etkilemiştir. İnsan sağlı̆̆ına hizmet etmek amacı ile günümüzde pek çok hastane, teknolojinin kendilerine sağladığ 1 imkânları kullanarak, kaliteli ve güvenli hizmet sunmayı hedeflemektedir.

Biz bu çalışmada; Yozgat Şehir Hastanesi'nde, bilgi yönetim sistemine entegre ettiğimiz, enfeksiyon kontrol önlemlerini içeren klinik karar destek sistemlerinin hazırlanma süreci ve etkinliğini sunmayı amaçladık.

\section{GEREÇ VE YÖNTEM}

Çalışmamız İç Anadolu Bölgesi'nde bulunan ve Türkiye'nin ilk şehir hastanesi olan, Yozgat Şehir Hastanesi'nde yapılmıştır. Hastanemiz 475 servis yatağı ve 60 yoğun bakım yatağına sahiptir. Hizmete başlama tarihinden (16.01.2017) günümüze kadar günlük ortalama 3000 poliklinik hastası bakılmaktadır ve ortalama $\% 80$ yatak doluluk oranı ile hizmet vermektedir. Hastane bilgi yönetim sistemi olarak, AKGÜN yazılım (Akgün Bilgisayar Program ve Hizm. San. Tic.Ltd. Şti), web tabanlı uygulaması ile hizmet vermektedir.

Hastanemizde, Enfeksiyon Kontrol Komitesi (EKK) tarafından, hastane enfeksiyonlarını önlemeye yönelik aktif takipler yapılmaktadır. Tüm kültür üremeleri günlük takip edilerek, hasta ve sağlık çalışanlarını korumaya yönelik, gerekli izolasyon önlemleri uygulanmaktadır. Üç enfeksiyon hastalıkları ve klinik mikrobiyoloji uzman doktoru, ve iki enfeksiyon kontrol hemşiresi ile koordineli bir çalışma yürütülmektedir.
Hastane enfeksiyonlarını önlemeye yönelik çalışmalarımızda, zaman kaybını ortadan kaldırmak ve insan kaynaklı hata riskini minimize etmek üzere, klinik karar destek sistemleri (KDS) oluşturduk. KDS aracılığı ile hastanın kendi hekimi ve hemşiresinin ekranına, hastaya özel bilgi notlarının çıkmasını sağladık. Hastane bilgi yönetim sistemi yazılımına, belirlediğimiz tetikleyici faktörler kodlanarak, her bir tetikleyiciye özel uyarılar hazırladık.

\section{KDS planlamamızı üç tetikleyici başlık altında yaptık.}

\section{1- Tanı ile tetiklenen KDS}

\section{2- Laboratuvar sonucu ile tetiklenen KDS}

\section{3- İlaç ile tetiklenen KDS}

Hastanın HBYS sistemine girilen tanıs1, laboratuvar tarafindan onaylanan kültür sonucu veya hekim tarafından hastaya yazılan ilaç baz alınarak, her biri için ayrı ayrı tetikleyici faktörler tanımladık. Hastaya, daha önceden tarafımızca tanımlanarak, yazılım sistemine kodladığımız bir tetikleyici faktör devreye girdiğinde, HBYS sistemi üzerinden hasta ile ilişkili işlem yapan tüm sağlık çalışanlarına (kendi hekimi, konsültasyonda değerlendiren hekimi, hemşiresi, hastayı gören diyetisyen ve fizyoterapist gibi yardımcı sağlık personeli) belirlenmiş uyarılar görünmektedir. Hazırladığımız tetikleyici faktörler ve oluşturduğumuz uyarılar Tablo 1'dE gösterilmiştir.

\section{BULGULAR}

Çalışmamız, Yozgat Şehir Hastanesi'nde, bilgi yönetim sistemine entegre ettiğimiz, enfeksiyon kontrol önlemlerini içeren klinik karar destek sistemlerinin hazırlanma süreci ve etkinliğini sunmak amacı ile yapılmıştır. Şehir Hastanesi 16.01.2017 tarihinde hizmete girmiş olup, yaklaşık 10 aydır hasta kabul etmektedir. Hastanemizde, hazırladığımız karar destek sistemleri iki aydır aktif olarak kullanılmaktadır. Hastanemiz, 141.235 $\mathrm{m}^{2}$ kapal1 alana sahip olup, ortalama $\% 80$ doluluk oranı ile hizmet vermektedir. Hastanemizin açıldığı tarihten (16.01.2017) günümüze kadar yatan hasta sayıları ve EKK tarafindan izolasyon uyguladığımız hasta sayıları grafikte gösterilmiştir.

Hastanemizde enfeksiyon kontrol önlemlerine yönelik hazırladığımız KDS'ler kullanıma girdikten sonraki dönem ve kullanılmadan önceki dönem karşılaştırıldığında, herhangi bir kültüründe izolasyon uygulamayı gerektirecek bir mikroorganizma üreyen hastaya ulaşma süremiz ve izolasyona başlama süremiz belirgin olarak azalmıştır. 


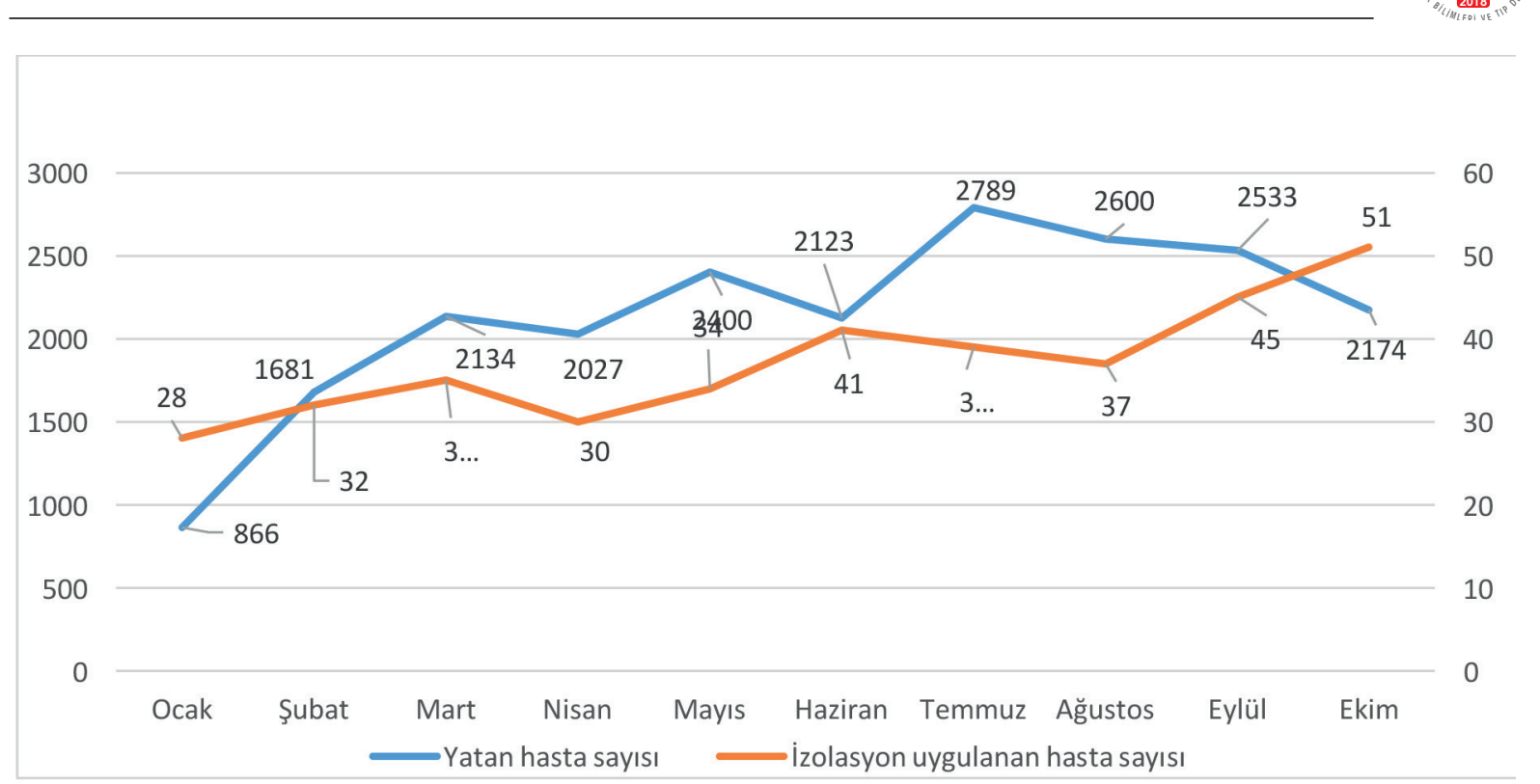

Grafik 1. Aylara göre yatan hasta sayısı ve izolasyon uygulanan hasta sayısı

\section{TARTIŞMA}

T1bbi hataları azaltma, sağlık kalitesi ve verimliliğini artırma potansiyeli nedeniyle klinik karar destek sistemleri, sağlık uygulama merkezlerinde önemli bir yer tutmaya başlamıştır $(2,3)$. Aynı zamanda KDS tasarımları, teknolojinin sağladığı geniş imkânlar kul- lanılarak, sağlıkta farklı platformlar geliştirilmesine yardımcı olmaktadır (4). Biz çalışmamızda, tasarladığımız KDS formatları ile, hastane enfeksiyonlarını önleme ve gelişebilecek enfeksiyonlara en kısa sürede müdahale edebilmeyi amaçladık. Literatüre bakıldığında, enfeksiyon kontrol önlemlerine yönelik karar destek sistemlerinin kullanımı yaygın değildir

Tablo 1. Tetikleyici faktörler ve uyarı sistemi

\begin{tabular}{|c|c|c|c|}
\hline $\begin{array}{l}\text { Tetikleyici } \\
\text { Laboratuvar } \\
\text { Sonuçları }\end{array}$ & $\begin{array}{l}\text { Tetikleyici } \\
\text { Tanılar }\end{array}$ & $\begin{array}{l}\text { Önerilen İzolasyon } \\
\text { Önlemleri: Uyarı } \\
\text { ekranında görülen }\end{array}$ & Uyulması gereken öneriler: Uyarı ekranının içeriği \\
\hline $\begin{array}{l}\text { Solunum örneklerinde } \\
\text { Tüberküloz (TB) basili }\end{array}$ & $\begin{array}{l}\text { Kızamık } \\
\text { Suçiçeği } \\
\text { Larenks TB } \\
\text { Akciğer TB }\end{array}$ & $\begin{array}{l}\text { Standart izolasyon } \\
\text { önlemlerine ek olarak: } \\
\text { Lütfen solunum } \\
\text { izolasyonu uygulayınız }\end{array}$ & $\begin{array}{l}\text { Mümkünse hastayı tek kişilik ve negatif basınçlı odada takip } \\
\text { ediniz. Hasta odasına girerken N95 veya FFP } 3 \text { tipi maske } \\
\text { takınız. Hastanın odadan çıkması gerekecekse, hastaya } \\
\text { cerrahi maske takınız. Gerekli durumlarda Enfeksiyon Kontrol } \\
\text { Komitesi ile irtibata geçiniz. }\end{array}$ \\
\hline $\begin{array}{l}\text { Kırım Kongo } \\
\text { Kanamalı } \\
\text { Ateşi PCR }\end{array}$ & $\begin{array}{l}\text { Kırım } \\
\text { Kongo Kanamalı } \\
\text { Ateşi }\end{array}$ & $\begin{array}{l}\text { Standart izolasyon } \\
\text { önlemlerine ek olarak: } \\
\text { Lütfen temas ve } \\
\text { damlacık izolasyonu } \\
\text { uygulayınız }\end{array}$ & $\begin{array}{l}\text { Mümkünse hastayı tek kişilik ve negatif basınçlı odada takip } \\
\text { ediniz. Hasta odasına girerken N95 veya FFP } 3 \text { tipi maske } \\
\text { takınız. Hastanın odadan çıkması gerekecekse, hastaya cerrahi } \\
\text { maske takınız. Hasta ile veya çevresindeki cansız yüzeylerle } \\
\text { temas ederken steril olmayan temiz eldiven giyiniz. Hasta ile } \\
\text { veya odasındaki yüzeylerle temasın fazla olmasının beklendiği } \\
\text { durumlarda, hastada idrar veya gaita inkontinansı, ileostomi, } \\
\text { kolostomi veya açık drenaj varlığında odaya girerken eldivene } \\
\text { ek olarak steril olmayan temiz bir önlük giyiniz. Eldiven ve } \\
\text { önlük hasta odasını terk etmeden önce veya hasta başından } \\
\text { ayrılırken çıkarınız. Gerekli durumlarda Enfeksiyon Kontrol } \\
\text { Komitesi ile irtibata geçiniz. }\end{array}$ \\
\hline $\begin{array}{l}\text { MRSA } \\
\text { Acinetobacter } \\
\text { baumannii } \\
\text { P.aeruginosa } \\
\text { ESBL-pozitif } \\
\text { Klebsiella, ESBL-pozitif } \\
\text { E.coli, VRE, C.difficile, } \\
\text { Enterohemorajik E. coli }\end{array}$ & $\begin{array}{l}\text { Kutanöz difteri } \\
\text { İmpetigo } \\
\text { Herpes simplex } \\
\text { İnfeksiyonu } \\
\text { (neonatal veya } \\
\text { mukokütanoz) }\end{array}$ & $\begin{array}{l}\text { Standart izolasyon } \\
\text { önlemlerine ek olarak: } \\
\text { Lütfen temas izolasyonu } \\
\text { uygulayınız }\end{array}$ & $\begin{array}{l}\text { Mümkünse hastayı tek kişilik odada takip ediniz. Hasta ile veya } \\
\text { çevresindeki cansız yüzeylerle temas ederken steril olmayan } \\
\text { temiz eldiven giyiniz. Hasta ile veya odasındaki yüzeylerle } \\
\text { temasın fazla olmasının beklendiği durumlarda, hastada idrar } \\
\text { veya gaita inkontinansı, ileostomi, kolostomi veya açık drenaj } \\
\text { varlığında odaya girerken eldivene ek olarak steril olmayan } \\
\text { temiz bir önlük giyiniz. Eldiven ve önlük hasta odasını terk } \\
\text { etmeden önce veya hasta başından ayrılırken çıkarılmalıdır. } \\
\text { Gerekli durumlarda Enfeksiyon Kontrol Komitesi ile irtibata } \\
\text { geçiniz. }\end{array}$ \\
\hline
\end{tabular}


(5). Yakın tarihli bir meta-analizin parçası olarak, Cresswell ve ark. (6), karar destek sistemlerini incelemiş ve sağlık profesyonelleri ile ilişkili 41 kullanım alanını özetlemiştir. Bunlardan hiç birisi enfeksiyonu önlemeye yönelik değildir. Bu nedenle çalışmamız, KDS'lere yeni bir bakış açısı sağlaması, ülkemiz ve dünya sağlık politikalarında en önemli yer tutan, hastane enfeksiyonlarını önleme çalışmalarına katkı sağlaması açısından değerlidir.

Enfeksiyon kontrol önlemlerine ilişkin az sayıdaki KDS çalışmalarından birinde, Evans ve ark. (7), yalnızca metisilin dirençli Staphylococcus aureus kolonizasyon riski bulunan hastaları, hemşire istasyonlarına bildiren bir çalışma yapmış ve gerekli uyarılar belirlemişlerdir. Bizim çalışmamız ise, tüm hastane birimlerini ve tüm yatan hastaları değerlendiren ve tek bir mikroorganizmaya odaklı olmayip, hem hastanın tanısı hem de herhangi bir kültüründe izolasyon gerektiren bakteri üremelerini kapsamaktadır. Aynı zamanda, yalnızca hemşirelere yönelik bir uyarı sistemi olmayip, hastanenin herhangi bir birimindeki hastaya, herhangi bir sağlık çalışanının, hastane bilgi sistemi üzerinden uyarıları görebileceği şekilde tasarlanmıştır.

Hazırladığımız KDS sistemi, iki aydır aktif olarak kullanılmaktadır. Hastane enfeksiyon oranlarına etkisini ve maliyet analizini belirlemek için süre yeterli değildir. Fakat, bu kısa süre içerisinde çalışmamızın olumlu yansımaları alınmış̧ır. Bu sistem sayesinde izolasyon uygulanması gereken hastalara, zaman kaybı olmaksızın, etkin ve doğru izolasyon önlemleri uygulanabilmektedir. İki aylık dönemde, KDS uygulamalarının yapılmadığı döneme oranla, çok daha kısa sürede gerekli önlemler alınabilmiş, uygulama süresi olarak eski sisteme göre anlamlı derecede düşüş saptanmıştır. Hazırladığımız KDS sisteminin, maliyet etkinliği ve enfeksiyon oranlarımıza istatistiki etkisi ilerleyen süreçte ortaya konabilecektir.

\section{SONUC}

Hazırladığımız KDS tasarımımızın, dünya çapında, sağlık politikalarının üst sıralarında yer alan hastane enfeksiyonlarını önleme çabalarına, olumlu bir katkı sağlayacağı düşüncesindeyiz. Bu alanda, farklı çalışmalar ve uygulamaların geliştirilmesi, günümüz hastane teknolojilerinin sağladığı imkanlar sayesinde, her alanda karar destek sistemlerinin, hasta ve çalışan güvenliğini arttıracak şekilde planlanarak yaygınlaştırılmasi gerekmektedir.

\section{DECLARATION OF CONFLICTING INTERESTS}

The author declared no conflicts of interest with respect to the authorship and/or publication of this article.

\section{KAYNAKLAR}

1. Yataklı Tedavi Kurumları Enfeksiyon Kontrol Yönetmeliğinde Değişiklik Yapılmasına Dair Yönetmelik. Resmi Gazete: 25 Haziran 2011-27975.

2. Bates DW, Cohen M, Leape LL, et al. Reducing the frequency of errors in medicine using information technology. J Am Med Inform Assoc 2001; 8: 299-308.

3. Teich JM, Wrinn MM. Clinical decision support systems come of age. MD Comput 2000; 17: 43-6.

4. Ji-In Woo BS, Jung-Gi Yang BS, Young-Ho Lee, Un-Gu $\mathrm{K}$. Healthcare decision support system for administration of chronic diseases. Healthc Inform Res 2014 July; 20: 173-82.

5. Marc-Oliver Wright MT,Ari Robicsek. Clinical decision support systems and infection prevention: To know is not enough. Am J Infect Control 2015; 43: 554-8.

6. Cresswell K, Majeed A, Bates DW, Sheikh A. Computerised decision support systems for healthcare professionals: an interpretive review. Inform Prim Care 2012; 20: 115-28.

7. Evans RS, Wallace CJ, Lloyd JF, et al. Rapid identification of hospitalized patients at high risk for MRSA carriage. J Am Med Inform Assoc 2008; 15: 506-12.

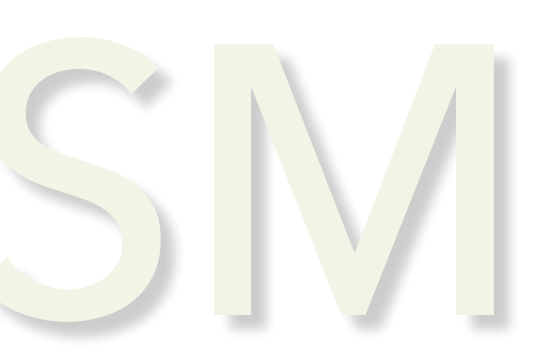

